\title{
SOCIOAFETIVIDADE: O VALOR JURÍDICO DO AFETO E SEUS EFEITOS NO DIREITO PÁTRIO
}

\section{SOCIOAFFECTIVITY : THE JURICAL VALUE OF AFFECTION AND ITS EFFECTS IN THE COUNTRY LAW}

\author{
Vinicius Pinheiro Marques ${ }^{1}$ \\ Nadhya Sousa Santana ${ }^{2}$
}

\section{RESUMO}

Este artigo tem como objetivo estudar o estado de filiação socioafetivo e os efeitos pessoais e materiais decursivos do seu reconhecimento, à luz do Texto Constitucional de 1988 garantiu tratamento igualitário aos filhos havidos ou não da relação conjugal, vedando quaisquer formas de discriminação. Será demonstrado que não se pode desprezar as relações paternas e/ou maternas- filiais consubstanciadas apenas na afetividade, no qual o filho afetivo tem o direito de ter o pai e/ou mãe socioafetivo reconhecido de forma legal, a ter essa filiação no assento registral. Com isso, demonstrar-se-á que a carga genética não é condição única e determinante de ser pai ou mãe, haja vista que a relação da maternidade e/ou paternidade é desenvolvida com a convivência familiar. Assim, necessário é compreender que o afeto tem o papel determinante para o pleno desenvolvimento do menor, como também é primordial na construção do vínculo afetivo de pais e filhos. A metodologia empregada na pesquisa foi o método de abordagem dedutivo, através do estudo doutrinário e análise da legislação.

Palavras-Chave: Afeto; Efeitos Jurídicos da Filiação; Filiação; Socioafetividade.

\section{ABSTRACT}

This article aims to study the state of socio-affective filiation and the personal and material effects that occurs due to its recognition, in which the Constitution of 1988 Letter guaranteed an

\footnotetext{
${ }^{1}$ Doutor em Direito pela Pontifícia Universidade Católica de Minas Gerais. Professor do Curso de Direito e do Programa de Pós-Graduação em Prestação Jurisdicional e Direitos Humanos da Universidade Federal do Tocantins. Advogado.E-mail: viniciusmarques@mail.uft.edu.br

${ }^{2}$ Bacharel em Direito pela Faculdade Católica do Tocantins .
} 
igualitary treatment to the children borned or not in a marital relationship, prohibiting any type of discrimination. It will be demonstrated that the paternal and/or maternal relationships consubstantiated only in socio-affective filiation cannot be despised, whereupon the affective son has the right to have his socio-affective father and/or mother recognized in the legal form, there after having his filiation registered. Thereby, it will be demonstrated that genetic load it is not the only and decisive condition to be a father or a mother, given the maternal and/or paternal relationship developed in the family interation. Thus, it's necessary to understand that affection has a crucial role for a full development of the child, as much as building an affective bond among parents and children is primordial. The methodology used in this research was the method of deductive approach, through a doctrinal study and a legislation analysis.

Key-words: Affection; Filiation; Juridical effects of filiation.; Socio-affective.

\section{INTRODUÇÃO}

Com a evolução social percebe-se que a sociedade passa a ter sucessivas transformações, em decorrência das variações no espaço e tempo, de tal forma que a família nuclear passa a mudar o seu conceito e estrutura.

Pode observar que a concepção outrora que se tinha de família era aquela composta por uma figura paterna (homem), figura materna (mulher) e a prole. Entretanto hodiernamente a estrutura familiar não é mais composta basicamente com a prole comum dos nubentes, bem como a figura paterna e/ou materna não é mais restrita pelo elo genético ou presunção legal, mas pela convivência afetiva.Soma-se ainda que a Carta Constitucional equiparou o tratamento aos filhos, assim, sendo eles havidos dentro ou não do matrimônio, passam a ter direitos igualitários, sendo vedada qualquer forma de discriminação.

O estado de filiação é um conjunto de direitos e obrigações dos genitores para com seus filhos no qual aqueles possuem a responsabilidade de suprir as necessidades havidas em decorrência do poder famíliar a fim de proporcionar o pleno desenvolvimento da criança e do adolescente.

Sob essa ótica surge a discussão sobre o direito ao reconhecimento a filiação socioafetiva no qual se aprecia o valor jurídico do afeto na convivência familiar. $E$ dessa maneira vê-se necessário proteger juridicamente aqueles que são tidos como 
filho, mesmo que não possuam laço biológico, com propósito de garanti-Ihes o direito da filiação afetiva no assento de nascimento e os efeitos jurídicos desinentes.

Assim, em um primeiro momento, o presente trabalho através da análise legislativa e entendimento doutrinário demonstrará a desbiologização do conceito de família reconhecendo o valor jurídico do afeto consubsitanciado principalmente nos princípios dignidade da pessoa humana e da afetividade no ambiente de convivência família.

Observar-se-á que as relações paterno-filiais e/ou materno-filiais não podem mais ser consideradas tão somente de acordo com o vínculo hereditário consanguíneo, haja vista que pai e/ou mãe são aqueles que ofertam amor, participam ativamente na vida do filho, arcam com ônus material e lhes dão afeto. Logo é correto o ditado que diz: pai/mãe é aquele(a) que cria.

Ademais, em momento posterior, examinar-se-á os direitos pessoais decorrente do reconhecimento da socioafetividade estabelecida, enfatizando que 0 filho independente da origem filial, tem direito ao nome, a parentalidade registral e a convivência familiar. Neste tópico ainda abordará que é possível judicialmente pleitear a multiparentalidade registral isto é, diante no caso concreto o magistrado à luz do princípio da proteção integral e dignidade humana poderá permitir a inclusão no registro de nascimento o nome do pai ou mãe socioafetivo permanecendo ainda o nome de ambos os pais biológicos, e vice-versa.

Por fim, em último capítulo, irá se destacar os direitos patrimoniais dada a qualidade de filho estabelecida surgida no mundo jurídico, sendo esses o dever de prestar alimentos e os direitos sucessórios.

Como fonte de estudo será utilizada a legislação pátria vigente e os conceitos e apontamentos trabalhados pelos doutrinadores acerca do tema a ser pesquisado. 


\section{A EVOLUÇÃO DO AFETO ENQUANTO VALOR JURÍDICO}

A família é a base fundamental da sociedade e com a evolução social sofre constantes mudanças de origem, composição, estrutura e de modo consequente a sua concepção. Preconiza Venosa (2017, p.03) que "entre os vários organismos sociais e jurídicos, o conceito, a compreensão e a extensão de família são os que mais se alteraram nos curso dos tempos".

A célula básica da família, formada por pais e filhos, não se alterou muito com a sociedade urbana. A família atual, contudo, difere das formas antigas no que concerne a suas finalidades, composição e papel de pais e mães. (VENOSA, 2017, p.5)

Necessário é compreender que um grupo familiar é formado a partir do afeto, bem como será o vínculo afetivo que irá refletir no desenvolvimento de seus membros.

Família, afinal, é o lugar privilegiado da realização da pessoa, pois é aí que se inicia e se desenvolve todo o processo de formação da personalidade do sujeito. A família deixou, portanto, de ser um núcleo econômico e de reprodução para ser o espaço do amor e do afeto. (PEREIRA, 2009, p.2)

Neste contexto o direito surge com a finalidade de reconhecer a entidade familiar e dar proteção legal definindo um conceito próprio para o que é família. Contudo, o legislador deve adaptar a norma legal as constantes transformações ocorrida na sociedade.

Nas antigas civilizações, como na Roma, a família não era construída com base no afeto, mas sim pelo culto doméstico onde prestavam cultos aos seus antepassados. Como bem assevera Venosa (2017, p.4) "No Direito Romano, assim como no grego, o afeto natural, embora pudesse existir, não era o elo de ligação entre os membros da família. Nem o nascimento nem a afeição foram fundamento da família romana".

Convém aduzir que o vocábulo afeto mesmo tendo uma conotação abstrata pode ser compreendido pelo sentimento nutrido de carinho e cuidado que as pessoas 
desenvolvem mutuamente. E dentro da estrutura familiar é considerado primordial para a bom relacionamento entre aqueles que compõe o seio familial.

Ademais, sob o prisma da criança, o vínculo afetivo tem um papel de grande importância no seu pleno desenvolvimento haja vista que é durante a infância que irá se criar o vínculo com seus genitores e demais componentes do grupo familiar que está inserido.

No Brasil, com advento do Código Civil de 1916, o direito de família também pouco se preocupou com o vínculo afetivo, haja vista que a filiação era classificada consoante a origem, ou seja, os filhos havidos dentro do matrimônio eram considerados legítimos, já aqueles advindos de uma relação extramatrimonial eram tidos como ilegítimos, e, por conseguinte, não recebiam a mesma proteção jurídica do legislador.

O revogado Código mencionado, no qual vigorou por mais de 80 anos, ao dispor em seu art. 332 que "o parentesco é legitimo, ou ilegítimo, segundo procede, ou não de casamento; natural, ou civil, conforme resultar de consanguinidade, ou adoção", trouxe severas distinções quanto o reconhecimento da filiação, ora não estabeleceu tratamento isonômico entre a prole.

Todavia, deve-se compreender que o direito a filiação ultrapassa o vínculo matrimonial e sanguíneo, no qual o seu reconhecimento não pode ser obstado pela pseudo imagem da indissolubilidade do casamento. Ora, o filho havido dentro ou fora do casamento, com ou sem elo biológico, tem do direito de ter trato isonômico, bem como ser reconhecido legalmente.

O afeto, com ou sem vínculos biológicos, deve ser sempre o prisma mais amplo da família, longe da velha asfixia do sistema patriarcal do passado, sempre em prol da dignidade humana. Sabido é que os sistemas legais do passado não tinham compromisso com o afeto e com a felicidade". (VENOSA, 2017, p.8)

Com a promulgação da Constituição da República Federativa do Brasil rompese com distinção dos filhos legítimos e ilegítimos sendo instaurando uma nova ordem social, instituindo como um dos princípios fundamentais a dignidade da pessoa 
humana. Foi inserido a seguinte disposição no art. $227 \S 6^{\circ}$," os filhos, havidos ou não da relação do casamento, ou por adoção, terão os mesmos direitos e qualificações, proibidas quaisquer designações discriminatórias relativas à filiação".

É a dignidade da pessoa humana que permite e determina que seja destinado tratamento igualitário aos filhos, independentemente de sua origem, se advêm ou não do casamento. Por ser princípio fundamental, dita um limite de atuação do Estado e garante que a partir dele se promova a dignidade da pessoa humana, valor espiritual e moral inerente à pessoa. (ZENI, 2009, p.70)

Desenhou-se um novo modelo familiar refletindo na elaboração de um novo Código Civil, então promulgado em 2002, no qual é alicerçado em princípios básicos como solidariedade, liberdade, afetividade e a igualdade. Além de não mais estabelecer diferenças sob o prisma jurídico da prole de relações não matrimoniais passou-se também a tutelar a equiparação da filiação do filho socioafetivo.

O Código Civil de 2002, ao reconhecer parentesco nas relações socioafetivas, ex vi art.1.593, ampliou as possibilidades fáticas de filiação, como veio reconhecer o Superior Tribunal de Justiça: “... Por filhos de qualquer condição deve-se entender, também, aquela pessoa que foi acolhida, crida, mantida e educada pelo militar, como se filha biológica fosse, embora não tivesse com ele vínculo sanguíneo..."." (NADER, 2016, p.313)

Vê-se que o legislador reconheceu a importância do afeto nas relações parentais sendo possível afirmar que o vínculo afetivo possui valor jurídico.

Nesse diapasão, dos aspectos ligados à filiação, no que se refere aos direitos equitativos independentemente de vínculo biológico, conclui-se que o ordenamento jurídico atribuiu, implicitamente, valor jurídico ao afeto, não sendo somente um aspecto social ou psicológico. Assim, a filiação baseada na relação afetiva merece o mesmo patamar de igualdade e reconhecimento, considerandose a afetividade como base das relações filiais. (ANDRADE, 2014, p.2)

Destarte, importante trazer à baila que pode-se analisar o afeto sob dois aspectos: primeiro quanto seu papel essencial para o desenvolvimento pleno da criança 
dentro do arranjo familiar; e segundo como elemento caracterizador para o reconhecimento da paternidade e/ou maternidade socioafetiva.

Domingos (2013, p.11) ensina que, "[...], colmatado o arranjo familiar na linha da afetividade encontra-se o novo papel da família para a criança, pois terá ela o meio natural ao seu pleno desenvolvimento, aliás, direito fundamental que não se deve sequer mitiga-lo".

Pode-se afirmar que a ligação afetiva entre a criança e sua família é indispensável para garantir a formação psicológica saudável do futuro adulto. Será no familiar que a criança buscará apoio, orientação, proteção e referência para o desconhecido e terá suporte para suportar os dessabores surgidos ao longo do seu desenvolvimento biológico.

Nos primeiros anos de vida, a criança depende das ligações familiares para crescer. Ela carece de cuidados com o corpo, com alimentação e com a aprendizagem. Mas nada disso é possível se ela não encontrar um ambiente de acolhimento e afeto. Os bebês não sobrevivem ao desamor. (OLIVEIRA; COLLET, 1999, p.96)

Desse modo, pode-se asseverar que as experiências vivenciadas pelo jovem, tanto no contexto familiar quanto nos outros ambientes nos quais ele está inserido, contribuem diretamente para a sua formação enquanto adulto, sendo que, no âmbito familiar, o indivíduo vai passar por uma série de experiências genuínas em termos de afeto, dor, medo, raiva e inúmeras outras emoções, que possibilitarão um aprendizado essencial para a sua atuação futura.( PRATTA; SANTOS, 2007, p.252)

Um grupo familiar centrado em uma relação afetiva proporcionará que a criança se sinta amada, querida, cuidada por seus genitores e os demais membros garantindoIhe um desenvolvimento psicofísico.

Nesse compasso preconiza o preâmbulo da Convenção sobre os Direitos da Criança que a família, além de ser um organismo fundamental da sociedade, é um ambiente natural de crescimento e bem-estar dos membros e em especial dos filhos menores. $O$ referido diploma normativo comanda ainda que a criança, para ter o pleno e 
harmonioso desenvolvimento da sua personalidade, necessitar crescer em um ambiente saudável, pautado em felicidade, amor e compreensão.

Interessante destacar que nas relações de adoção percebe-se nitidamente que é um arranjo familiar baseado em um elo de afetividade onde os futuros pais e filhos em que se escolhem pelo afeto mútuo.

É clarividente que a conceito de família tendo como base somente a familia patriarcal traçada pelo elo biológico decaiu com os novos arranjos contemporâneos uma vez que nestes o pressuposto afetividade é o pilar da relação de convivência e alicerce emocional.

Sendo assim, inadmissível se mostra dar qualquer preponderância a núcleo familiar ou dimensionar que a família biológica seja o núcleo insofismável e insubstituível para a permanência da criança. Há que se entender que a criança precisa conhecer e vivenciar o amor, carinho, afeto e estes predicados não decorrem, necessariamente, da vinculação biológica. Evidente que a preponderância do direito fundamental da criança está em crescer dentro de família natural, estruturada e capaz de lhe proporcionar um ambiente saudável, livre de violências, ou seja, crescer e vivenciar um ambiente de afetividade. (DOMINGOS, 2013, p.12)

Seja na família natural, ou substituta, há que se garantir que a criança viva e cresça em um ambiente saudável, sendo Ihe resguardado seus direitos fundamentais como a saúde, educação, lazer, convivência familiar e comunitária, dentre outros.

Como bem assegura o legislador ordinário, nos art. $3^{\circ}$ e $7^{\circ}$ da lei $n^{\circ}$ 8.069/90 Estatuto da criança e adolescente -, importante destacar que no comando do art. $7^{\circ}$ determina que tanto para a criança quanto o adolescente são Ihes assegurados o desenvolvimento sadio e harmonioso no seio familiar e dentro da comunidade no qual está inserido em condições dignas de existência de modo a dar efetividade ao princípio da dignidade da pessoa humana.

Imperioso ressaltar que prezar pelo afeto é importante não só para o desenvolvimento da criança dentro de um contexto social, mas para do grupo familiar que está inserido. Sob o aspecto normativo verifica-se que legislador disciplinou, no art. 
1.593 do CC/02, como um dos pressupostos do reconhecimento do parentesco, além do sanguíneo e civil, o socioafetivo.

É incontestável o papel desempenhado pela família para que uma criança tenha um desenvolvimento sadio, e muito mais que um elo biológico, a afetividade dentro de uma família é imprescindível sendo responsável pelos laços recíprocos de afetivos de atenção, carinho e proteção.

Apenas a presença do pai ou da mãe biológicos não é garantia de que a pessoa se estruturará como sujeito. O cumprimento de funções paternas e maternas,por outro lado, é o que pode garantir uma estruturação biopsíquica saudável de alguém. E esta não precisa,necessariamente, ser exercida pelos pais biológicos. Por isso, a família não é apenas um dado natural, genético ou biológico, mas cultural, insista-se. (PEREIRA, 2009, p.3)

Ademais, nota-se a partir de precedentes judicias a valoração da afetividade nas relações familiares em especial quando trata-se na proteção integral do menor. Em que se há um grande número de decisões judiciais, lides fundadas no reconhecimento de paternidade ou alimentos, admitindo a paternidade socioafetiva e as consequências jurídicas dela decorrente.

Logo, observa-se que a finalidade do amparo jurídico é legítimo, afinal, teoricamente os membros da família socioafetiva se comportam e se relacionam como se fossem unidos biologicamente, de modo que, notório é sua luta pelo direito assecuratório, à medida que são famílias como tantas outras, talvez, mais "famílias" que as famílias tradicionais. (RODRIGUES; CONCIANI; 2015, p.118)

Em meio a todo esse contexto o termo afetividade culminou para o surgimento da família socioafetiva e, com enfoque neste trabalho, a filiação afetiva.

\subsection{Do estado de filiação socioafetivo}

Tartuce (2017, p.417) conceitua o instituto de filiação como " [...] a relação jurídica decorrente do parentesco por consanguinidade ou outra origem, estabelecida 
particularmente entre os ascendentes e descendentes de primeiro grau. Em suma, trata-se da relação jurídica existente entre os pais e os filhos". A filiação socioafetiva é constituída pela convivência entre um adulto e uma criança ou adolescente sem laço biológico que, no entanto, sob a ótica das relações sociais e emocionais, sua integralidade assemelha-se à de pai ou mãe e seu filho.

Isto posto, compreende-se que na parentalidade socioafetiva não há um vínculo legal (adoção), tampouco biológico, mas, sim o estado de posse de filho. Nesta relação o adulto educa, instrue, alimenta a criança como se filho seu fosse, sendo pública aquela relação que desenvolvida de pai e/ou mãe e filho.

Observa-se que na socioafetividade existe uma condição de pai e/ou mãe emocionalmente sendo bastante perceptível nos casos onde a criança não teve ou não tem o contato com um dos genitores biológicos seja por questões de dissolução conjugal, óbito, abandono efetivo, perda do poder familiar, e passa a conviver com então padrasto ou madrasta desenvolvendo uma relação de afeto e muitas vezes o chamando de pai ou mãe.

Dessarte, além do laço de afetividade, pressuposto indispensável para a condição do estado de filiação socioafetiva, são requeridos também o tempo de convivência, o laço de afeto deve ser sólido bem como reciproco, e a posse do estado de filho.

Salienta-se que, para alguns doutrinadores, há o entendimento de que para o reconhecimento da parentalidade socioafetiva é necessário somente demonstrar a posse de estado de filho. Esta nada mais é do que o animus de ser mãe ou pai no qual se dá o tratamento a criança como se filho seu fosse, Ihe proporcionando carinho, amor, proteção e nome, sendo está uma relação notória e continua.

Esse aspecto social, com o reconhecimento do afeto como fundante das relações parentais, aliada a um elemento volitivo daí decorrente, torna inafastável a consagração da posse de estado de filho como o instituto apto a permitir o acolhimento da filiação como fato socioafetivo. 
A segurança jurídica trazida pela posse de estado como forma de reconhecimento da situação de filiação se mostra pelos elementos constitutivos desse instituto: nominatio, tractatus e fama (ou reputatio).

$[\ldots]$

Há que existir notoriedade do estado de filho, ou seja, a posse de estado deve ser objetivamente visível no ambiente social. Outra qualidade necessária é a continuidade, ou seja, deve apresentar-se certa duração que revele estabilidade. Por derradeiro, esses fatos notórios e contínuos não devem gerar equívocos acerca da filiação.

Desse modo, a atribuição do nome, do tratamento de filho, bem como o reconhecimento social dessa relação devem ser notórios, estáveis e inequívocos. A caracterização da filiação socioafetiva a partir da posse de estado é, por conseguinte, aferida de modo objetivo, mantendo, desse modo, a segurança das relações sociais. Vê-se, por conseguinte, dimensão importante para solver os quesitos formulados na consulta. (FACHIN, 2012, p.13-14)

Cumpre ainda mencionar o Enunciado 519 do Conselho da Justiça Federal na V Jornada de Direito Civil no qual aduz ser imprescindível para o reconhecimento da parentalidade socioafetiva a posse do estado de filho.

Enunciado no 519: Art. 1.593: O reconhecimento judicial do vínculo de parentesco em virtude de socioafetividade deve ocorrer a partir da relação entre pai(s) e filho(s), com base na posse do estado de filho, para que produza efeitos pessoais e patrimoniais.

Assim, o estado de filiação afetivo é aquele em que o amor e o carinho recíprocos entre os membros suplantam qualquer grau genético, biológico ou social.

\section{DOS DIREITOS EXISTÊNCIAIS DECORRENTES DA SOCIAFETIVIDADE}

Conforme dispõe o preâmbulo da Constituição de 1988 instituiu-se no Brasil o Estado Democrático de Direito no qual assegura o exercício dos direitos sociais e individuais, bem como o bem-estar e a igualdade.

O texto do artigo 1ำ da Carta Política aduz que um dos fundamentos dessa nova ordem é a dignidade da pessoa humana. À luz do direito de família pode-se afirmar que o princípio da dignidade da pessoa humana está intrinsicamente ligado aos 
direitos da personalidade, no qual esses são os direitos subjetivos inerentes a pessoa, tais como direito ao nome, a filiação, a privacidade, a saúde, aos alimentos.

Da mesma maneira cumpre observar que o princípio da afetividade é um dos basilares do direito da família, no qual estar a ganhar destaque quando se trata da filiação afetiva.

Daí surge o princípio da afetividade, que decorre do princípio da dignidade da pessoa humana e tem alicerce na ordem constitucional baseado no entendimento de família como grupo social constituído basicamente nos laços afetivos, embora não seja um princípio expresso na Constituição Federal de 1988, a afetividade ganha ênfase nos julgamentos dos tribunais e na doutrina, perpetrando que o fator principal definidor da paternidade não seja mais a origem biológica, mas a afetividade comprovada nas relações. (ALMEIDA, 2015, p.58)

Sabe-se que o genitor tem o dever de proteger sua prole tanto no aspecto moral como material a fim de que estes possam ter uma vida digna, Ihes assegurando o pleno desenvolvimento e consequentemente o mínimo existencial.

Insta salientar que a Lei Maior, no teor do art. 229 dispôs que, "os pais têm o dever de assistir, criar e educar os filhos menores". Tal como no caput do art. 227, ordena que é dever da família, como também da sociedade e Estado, garantir à criança, ao adolescente e ao jovem, de forma prioritária, o direito à vida, à saúde, à alimentação, à educação, ao lazer, à profissionalização, à cultura, à dignidade, ao respeito, à liberdade e à convivência familiar e comunitária.

Sobre o tema, Sílvio Salvo Venosa (2017, p.409) acrescenta "O ser humano, desde o nascimento até sua morte, necessita de amparo de seus semelhantes e bens essenciais ou necessários para a sobrevivência". Não obstante, frisa-se que na estrutura do Código Civil de 2002 o livro IV destinou a Parte Especial ao direito de família, em que no título 1 traz os direitos pessoais, isto é, direitos extrapatrimoniais, fixando regras sobre o casamento, sua celebração, causas de impedimentos e suspensivas, validade e causas de dissolução, bem como a proteção da pessoa dos filhos. 
A proteção da pessoa dos filhos subordinados à autoridade paterna constitui dever decorrente do poder familiar, expressão esta considerada mais adequada que " pátrio poder", utilizado pelo Código de 1916. (GONÇALVES, 2017, p.21)

Neste ínterim, quando se postula o reconhecimento da filiação socioafetiva e este pedido é deferido, irá repercutir no mundo jurídico, haja vista que ato de reconhecer a socioafetividade gerará efeito erga omnes e decorrerá os mesmos efeitos patrimoniais e existências que goza a filiação terá biológica, gerando direitos e obrigações.

\subsection{Do direito ao nome}

Aduz Silvio Venosa (2017, p.249), em suas lições sobre o instituto da filiação, que "sob o aspecto do direito, a filiação é um fato jurídico do qual decorrem inúmeros efeitos. Sob perspectiva ampla, a filiação compreende todas as relações, e respectivamente sua constituição, modificação e extinção, que tem como sujeitos os pais com relações aos filhos".

Como se sabe o nome é um dos direitos essências da personalidade, não podendo apenas ser compreendido como uma forma de identidade social, mas também sob a perspectiva jurídica como personalidade da pessoa natural.

[...] o Código Civil elencou o direito ao nome como um dos direitos da personalidade do indivíduo, que o identifica perante a sociedade e, em razão de seu caráter personalíssimo, é inauferível, imprescritível, inalienável e absoluto. (ALMEIDA, 2015, p.62)

Cabe observar o pensamento de Nery (2014, online) onde afirma que:

A pessoa ostenta como terceiro atributo de sua individualidade o nome. Todos têm direito à identidade pessoal e o direito ao nome produz efeitos erga omnes. Por meio do nome, a pessoa é identificada como sujeito capaz de adquirir direitos e de cumprir obrigações, bem como é também identificada pela Administração Pública como súdito do Estado, sujeita aos direitos e deveres que suas relações de cidadão, a um só tempo, Ihe garantem e lhe impõem. 
Para Dias (2017) o nome dispõe de um valor que se insere no conceito de dignidade da pessoa humana. Assim sendo, os pais têm obrigação de registrar seus filhos, conferindo-Ihes um nome e filiação. Sobrevém-se que, uma vez reconhecida a filiação afetiva, surge o direito de retificar as certidões de nascimentos, a fazer constar o nome do pai ou da mãe socioafetiva.

\subsection{Do direito ao reconhecimento do estado filiativo afetivo}

Tartuce (2017, p.417) conceitua o instituto de filiação como "[...] a relação jurídica decorrente do parentesco por consanguinidade ou outra origem, estabelecida particularmente entre os ascendentes e descendentes de primeiro grau. Em suma, trata-se da relação jurídica existente entre os pais e os filhos".

O direito ao reconhecimento do estado de filiação tem como características a imprescritibilidade, indisponibilidade e é personalíssimo.

O vigente Código Civil, considerando o bem-estar da família e principalmente observando o princípio da proteção integral ao menor, prescreve que o reconhecimento dos filhos havidos extraconjugal poderá ser feito em conjunto ou separadamente pelos genitores junto ao Cartório de Registro de Pessoas Físicas pelo assento de nascimento, por testamento, mediante escritura ou outro documento público, qualquer que seja a origem da filiação, de modo a incluir a socioafetiva.

Salienta-se que o reconhecimento da filiação baseada no vínculo afetivo é um direito reciproco, no qual é interesse tanto dos "pais" quanto da criança em razão do princípio da igualdade, intuído pelo Constituição Federal.

À vista disso pode-se afirmar que tanto o pai e/ou mãe afetiva, bem como o menor, possuem interesse na propositura da ação, no qual o direito ao reconhecimento do vínculo afetivo é estendido a ambos. 
Importante trazer à baila o julgamento do Superior Tribunal de Justiça em sede do REsp no 1.059.214/RS, no qual reconheceu a filiação partena decorrente da sociafetividade.

\section{DIREITO DE FAMÍLIA. AÇAO NEGATÓRIA DE PATERNIDADE. EXAME DE DNA NEGATIVO. RECONHECIMENTO DE PATERNIDADE SOCIOAFETIVA. IMPROCEDÊNCIA DO PEDIDO.}

1. Em conformidade com os princípios do Código Civil de 2002 e da Constituição Federal de 1988, o êxito em ação negatória de paternidade depende da demonstração, a um só tempo, da inexistência de origem biológica e também de que não tenha sido constituído o estado de filiação, fortemente marcado pelas relações socioafetivas e edificado na convivência familiar. Vale dizer que a pretensão voltada à impugnação da paternidade não pode prosperar, quando fundada apenas na origem genética, mas em aberto conflito com a paternidade socioafetiva.

2. No caso, as instâncias ordinárias reconheceram a paternidade socioafetiva (ou a posse do estado de filiação), desde sempre existente entre o autor e as requeridas. Assim, se a declaração realizada pelo autor por ocasião do registro foi uma inverdade no que concerne à origem genética, certamente não o foi no que toca ao desígnio de estabelecer com as então infantes vínculos afetivos próprios do estado de filho, verdade em si bastante à manutenção do registro de nascimento e ao afastamento da alegação de falsidade ou erro.3. Recurso especial não provido.

Ademais, em detrimento o melhor interesse da criança, bem como sua proteção integral, o Supremo Tribunal Federal, no julgamento do ARE 692.186/DF, reconheceu a existência da repercussão geral na discussão da prevalência da paternidade socioafetiva em detrimento da paternidade biológica.

RECURSO EXTRAORDINÁRIO COM AGRAVO. DIREITO CIVIL. AÇÃO DE ANULAÇÃO DE ASSENTO DE NASCIMENTO. INVESTIGAÇÃ̃O DE PATERNIDADE. IMPRESCRITIBILIDADE. RETIFICAÇÃO DE REGISTRO. PATERNIDADE BIOLÓGICA. PATERNIDADE SOCIOAFETIVA. CONTROVÉRSIA GRAVITANTE EM TORNO DA PREVALÊNCIA DA PATERNIDADE SOCIOAFETIVA EM DETRIMENTO DA PATERNIDADE BIOLÓGICA. ART. 226, CAPUT, DA CONSTITUIÇÃO DA REPÚBLICA. AGRAVO PROVIDO PARA MELHOR EXAME DO RECURSO EXTRAORDINÁRIO.

Decisão: Cuida-se de Agravo em Recurso Extraordinário contra decisão que negou seguimento a Recurso Extraordinário interposto em face de acórdão prolatado pelo Superior Tribunal de Justiça, assim do: AGRAVO REGIMENTAL EM RECURSO ESPECIAL - AÇÃO DE INVESTIGAÇÃO DE PATERNIDADE C/C 
ANULAÇÃO DE REGISTRO - FILHO REGISTRADO POR QUEM NÃO É O VERDADEIRO PAI - RETIFICAÇÃO DE REGISTRO - IMPRESCRITIBILIDADE DIREITO PERSONALÍSSIMO - PRECEDENTES - RECURSO DESPROVIDO. Noticiam os autos que a ora agravada ajuizou Ação de Anulação de Assento de Nascimento c/c Investigação de Paternidade, tendo em vista que, quando do seu nascimento em 1961, fora registrada pelos avós paternos, como se estes fossem seus pais. Requereu fosse reconhecida a paternidade de seu pai biológico, para averbação junto ao Cartório de Pessoas Naturais e a anulação do registro feito pelos avós. O juízo monocrático julgou procedente a ação. Em sede de apelação a sentença foi mantida. Os ora recorrentes interpuseram Recurso Especial, ao qual foi negado seguimento, nos termos da ementa acima transcrita. Irresignados com o teor do acórdão prolatado, interpuseram recurso extraordinário, com fulcro no art. 102, III, da CRFB/88, apontando como violado o art. 226, caput, da Carta Constitucional. Alegam, em síntese, que a decisão do Superior Tribunal de Justiça, ao preferir a realidade biológica, em detrimento da realidade socioafetiva, não priorizando as relações de família que tem por base o afeto, afronta o referido dispositivo constitucional. $O$ extraordinário não foi admitido na origem. Em sequência, os recorrentes interpuseram o presente agravo. Finalmente, por entender que o tema constitucional versado nestes autos é relevante do ponto de vista econômico, político, social e jurídico, além de ultrapassar os interesses subjetivos da causa, esta Corte reconheceu a repercussão geral do tema constitucional. É o Relatório. DECIDO. O agravo preenche todos os requisitos de admissibilidade, de modo que o seu conhecimento é medida que se impõe. Ex positis, PROVEJO o agravo e determino a conversão em recurso extraordinário para melhor exame da matéria. À Secretaria para a reautuação do feito. Publique-se. Brasília, 04 de setembro de 2014.Ministro Luiz FuxRelatorDocumento assinado digitalmente

Outrossim, enquanto operador do direito, é preciso entender que não se pode limitar a titularidade somente a uma das partes, sob pena de hierarquizar 0 afeto entre 0 adulto e a criança, e atribuir carga valorativa no afeto de cada uma das partes envolvidas.

É importante mencionar que na legislação, como também nos entendimentos jurisprudenciais, não foi estabelecido um critério quanto a faixa etária para a possibilidade do reconhecimento da filiação socioafetiva, o qual não poderá ser obstado o reconhecimento após a maioridade ser atingida.

Por questão de coerência com tudo o que se defende acerca do instituto, e para não criar uma interpretação anti-isonômica, e por isso inconstitucional, [...] pois essa parentalidade pode se formar, também, após a maioridade daquele que é tratado como filho.(CASSETTARI, 2017, p.16) 
O direito não pode desamparar esta nova forma de filiação, mas sim estabelecer pressupostos para o seu reconhecimento, que não seja critério etário, a fim de dar efetividade aos princípios consagrados pelo ordenamento jurídico pátrio, como o da dignidade da pessoa humana, da proteção integral ao menor e da vedação discriminatórias à filiação.

Insta mencionar que, concernente a possibilidade do reconhecimento post mortem da filiação afetiva, Cassattari (2017, p.74) em sua obra aduz ser plenamente possível desde que em vida tenha existido uma relação afetiva e a posse de estado de filho. O enunciado 521 do Conselho da Justiça Federal compartilha deste entendimento.

Enunciado no 521 do CJF: Qualquer descendente possui legitimidade, por direito próprio, para propor o reconhecimento do vínculo de parentesco em face dos avós ou de qualquer ascendente de grau superior, ainda que o pai não tenha iniciado a ação de prova da filiação em vida.

Por fim, cumpre anotar que sendo preenchidos os requisitos para o reconhecimento filiação socioafetiva, quais sejam, a posse do estado de filho e o afeto ser mútuo, e se já transitou em julgado a ação que reconheceu a filiação, ou já houve o reconhecimento voluntário, de forma livre e espontânea, junto ao Cartório de Registro Civil das pessoas, não há que se falar em renúncia. Haja vista que o direito a personalidade é irrenunciável e indisponível.

Dessa forma, um pai que voluntariamente reconhece um filho não biológico como seu, efetuando o registro da paternidade, não poderá, posteriormente, contrariando o ato inicial praticado, contestar esta paternidade por meio de ação de anulação de registro de nascimento se o vínculo afetivo foi estabelecido por meio da posse de estado de filho. (ANDRADE, 2014, p.5)

Portanto, deve-se atentar que uma vez reconhecida a filiação, não importando qual vínculo fundamentado, é um ato irrevogável e não se tem o direito ao arrependimento, salvo se comprovado que o ato padece de vicio mais a ausência de qualquer relação afetiva desenvolvida. 


\subsection{Do direito à multiparentalidade}

Resta claro que o reconhecimento social e afetivo da parentalidade encontra-se recepcionada em nosso ordenamento jurídico. Contudo, o que ocorrerá se o filho afetivo já possui no assento registral a filiação biológica, é possível que o magistrado decida pela prevalência de umas das formas de parentalidade? Ou ainda que decida pela multiparentalidade?

Sendo um direito personalíssimo e indisponível, e com respaldo no princípio constitucional da dignidade da pessoa humana, o juiz poderá entender por uma das relações paterno/materno - filiais (biológico ou afetiva), e conforme o entendimento majoritário, a filiação afetiva vem prevalecendo em face da verdade biológica. Adotam socioparentalidade pelo bem-estar e equilíbrio emocional da criança ou do jovem.

É preciso compreender que há uma distinção em ser pai e/ ou mãe, e ser meramente genitor(a), pois a condição de ser pai ou mãe não é em razão biológica, mas sim em virtude de laços de afetividade que são formados no decorrer da convivência.

O que garante o cumprimento das funções parentais não é a relação genética ou derivação sanguínea, mas sim o cuidado e o desvelo dedicados aos filhos. [...] Para que um filho verdadeiramente se torne filho, ele deve ser adotado pelos pais, tendo ou não vínculos de sangue que os vinculem. A filiação biológica não é nenhuma garantia da experiência da paternidade, da maternidade ou da verdadeira filiação. Portanto, é insuficiente a verdade biológica, pois a filiação é uma construção que abrange muito mais o que uma semelhança entre os DNAs. (PEREIRA, 2009, p.3)

Consoante o entendimento doutrinário, admite-se o reconhecimento da multiparentalidade de modo que a criança possa ter no assento de nascimento o nome do pai e/ou mãe afetivos sem afastar a filiação consanguínea. Nota-se que o direito a multiparentalidade registral é um direito existencial da criança ou adolescente, de tal maneira que é irrenunciável e não pode sofrer limitação voluntária, só podendo vir a ser anulado por vício de manifestação de vontade ou vício material. 
Neste diapasão, orienta Buchmann (2013, p.59) que a não decretação da multiparentalidade onde for verificada, além de não dar eficácia ao princípio do interesse maior da criança e do adolescente, poderá acarretar prejuízos para esta na medida em que sofra abalos psicoemocionais.

Isto posto, a título de exemplo, se já houve o reconhecendo da filiação socioafetiva e este filho afetivo que até então não sabia quem eram seus pais biológicos e vem a pleitear a investigação da paternidade e/ou maternidade biológica, poderá este ter no assento de nascimento a filiação biológica e a socioafetiva simultaneamente.

A multiparentalidade é uma tendência com o novo modelo de arranjo familiar de forma que, com a evolução social, não há mais espaço para um único modelo de grupo familiar constituído pela relação matrimonial de um homem com mulher com sua prole comum.

Nesta esteira, insta destacar o recente jugaldo do Supremo Tribunal Federal acerca do assunto, julgamento do Recurso Extraordinário 898.060 SP, e da análise da Repercussão Geral 622, em que a corte decidiu, por maioria, que "a paternidade socioafetiva, declarada ou não em registro, não impede o reconhecimento do vínculo de filiação concomitante, baseada na origem biológica, com os efeitos jurídicos próprios". Veja-se:

EMENTA: RECURSO EXTRAORDINÁRIO. REPERCUSSÃO GERAL RECONHECIDA. DIREITO CIVIL E CONSTITUCIONAL. CONFLITO ENTRE PATERNIDADES SOCIOAFETIVA E BIOLÓGICA. PARADIGMA DO CASAMENTO. SUPERAÇÃO PELA CONSTITUIÇÃO DE 1988. EIXO CENTRAL DO DIREITO DE FAMÍLIA: DESLOCAMENTO PARA O PLANO CONSTITUCIONAL. SOBREPRINCÍPIO DA DIGNIDADE HUMANA (ART. 1ํㅡㄴ, III, DA CRFB). SUPERAÇÃO DE ÓBICES LEGAIS AO PLENO DESENVOLVIMENTO DAS FAMÍLIAS. DIREITO À BUSCA DA FELICIDADE. PRINCÍPIO CONSTITUCIONAL IMPLÍCITO. INDIVÍDUO COMO CENTRO DO ORDENAMENTO JURÍDICO-POLÍTICO. IMPOSSIBILIDADE DE REDUÇÃO DAS REALIDADES FAMILIARES A MODELOS PRÉ-CONCEBIDOS. ATIPICIDADE CONSTITUCIONAL DO CONCEITO DE ENTIDADES FAMILIARES. UNIÃO ESTÁVEL (ART. 226, § 3을 CRFB) E FAMÍLIA MONOPARENTAL (ART. 226, § 4ํ, CRFB).VEDAÇÃO À DISCRIMINAÇÃO E 
HIERARQUIZAÇÃO ENTRE ESPÉCIES DE FILIAÇÃO (ART. 227, § 6º, CRFB). PARENTALIDADE PRESUNTIVA, BIOLÓGICA OU AFETIVA. NECESSIDADE DE TUTELA JURÍDICA AMPLA. MULTIPLICIDADE DE VÍNCULOS PARENTAIS. RECONHECIMENTO CONCOMITANTE. POSSIBILIDADE. PLURIPARENTALIDADE. PRINCÍPIO DA PATERNIDADE RESPONSÁVEL (ART. 226, § 7ํ, CRFB). RECURSO A QUE SE NEGA PROVIMENTO. FIXAÇÃO DE TESE PARA APLICAÇÃO A CASOS SEMELHANTES.

[...]

3. A família, objeto do deslocamento do eixo central de seu regramento normativo para o plano constitucional, reclama a reformulação do tratamento jurídico dos vínculos parentais à luz do sobreprincípio da dignidade humana (art. 1ํㅡ. III, da CRFB) e da busca da felicidade.

[...]

8. A Constituição de 1988, em caráter meramente exemplificativo, reconhece como legítimos modelos de família independentes do casamento, como a união estável (art. 226, $\S 3^{\circ}$ ) e a comunidade formada por qualquer dos pais e seus descendentes, cognominada "família monoparental" (art. 226, $\S 4^{\circ}$ ), além de enfatizar que espécies de filiação dissociadas do matrimônio entre os pais merecem equivalente tutela diante da lei, sendo vedada discriminação e, portanto, qualquer tipo de hierarquia entre elas (art. 227, § $6^{\circ}$ ).

[...]

10. A compreensão jurídica cosmopolita das famílias exige a ampliação da tutela normativa a todas as formas pelas quais a parentalidade pode se manifestar, a saber: (i) pela presunção decorrente do casamento ou outras hipóteses legais, (ii) pela descendência biológica ou 4 (iii) pela afetividade.

[...]

12. A afetividade enquanto critério, por sua vez, gozava de aplicação por doutrina e jurisprudência desde o Código Civil de 1916 para evitar situações de extrema injustiça, reconhecendo-se a posse do estado de filho, e consequentemente o vínculo parental, em favor daquele utilizasse o nome da família (nominatio), fosse tratado como filho pelo pai (tractatio) e gozasse do reconhecimento da sua condição de descendente pela comunidade (reputatio).

13. A paternidade responsável, enunciada expressamente no art. $226, \S 7^{\circ}$, da Constituição, na perspectiva da dignidade humana e da busca pela felicidade, impõe o acolhimento, no espectro legal, tanto dos vínculos de filiação construídos pela relação afetiva entre os envolvidos, quanto daqueles originados da ascendência biológica, sem que seja necessário decidir entre um ou outro vínculo quando o melhor interesse do descendente for 0 reconhecimento jurídico de ambos.

$[\ldots]$

15. Os arranjos familiares alheios à regulação estatal, por omissão, não podem restar ao desabrigo da proteção a situações de pluriparentalidade, por isso que merecem tutela jurídica concomitante, para todos os fins de direito, os vínculos parentais de origem afetiva e biológica, a fim de prover a mais completa e adequada tutela aos sujeitos envolvidos, ante os princípios constitucionais da dignidade da pessoa humana (art. $1^{\circ}$, III) e da paternidade responsável (art. 226, $\S 7^{\circ}$ ).

16. Recurso Extraordinário a que se nega provimento, fixando-se a seguinte tese jurídica para aplicação a casos semelhantes: "A paternidade socioafetiva, declarada ou não em registro público, não impede o reconhecimento do 


\section{Vertentes do Direito}

\section{vínculo de filiação concomitante baseado na origem biológica, com todas as suas consequências patrimoniais e extrapatrimoniais"}

O ordenamento jurídico tem o papel de proporcionar aos cidadãos segurança jurídica, mesmo diante da omissão legislativa, por meio de fonte indiretas e de meios de integração normativa, assegurando o reconhecimento dessas famílias recompostas e todas as consequências jurídicas inerentes.

Destarte, hodiernamente é comum encontrar arranjos familiares em que o grupo familiar é composto pelos filhos de marido, filhos da esposa e os filhos comuns, no qual pelo convívio diário entre enteados e padrasto e lou madrasta, surge o que denominamos de pai e/ou mãe emocionalmente.

Sendo assim, pode-se compreender por famílias multiparentais aquelas que são formadas por pessoas que dissolveram relação marital ou de convivência e constituíram nova família, trazendo consigo filhos da relação anterior. Sendo notório nas relações em que a madrasta ou padrasto que ama e cuida do enteado como sendo seu filho, e a criança o ama como pai ou mãe, sem desconsiderar seus pais de origem genética.

Adverte Maluf (2014, p.14) que "a posição atual da jurisprudência é no sentido de negar a multiparentalidade, esclarecendo que a filiação será determinada por meio de um, ou de outro, critério e a sua determinação dependerá do caso concreto".

Com a evolução da sociedade é possível posteriormente ocorrer uma mutação constitucional, vez que na doutrina já há posicionamentos reconhecendo a multiparentalidade, de maneira a estabelecer a igualdade entre as filiações biológica e socioafetiva. 


\subsection{Do direito a convivência familiar}

Além dos direitos morais acima explanados, verifica-se também outros, que são o estado de família, no qual este é gênero, e o pátrio poder e as relações do parentesco são espécies.

O estado de família é um atributo da personalidade em que visa estabelecer a posição de cada indivíduo no ambiente familiar ao qual está inserido, bem como predeterminar seus efeitos legais, a regular direitos e deveres recíprocos. Tanto é verdade que o Código Civil regula as relações de parentesco e os efeitos produzidos, seja pela vinculo sanguíneo ou civil, ou ainda afetividade.

O estado de família se estabelece mediante o vínculo familiar entre as pessoas, em regra, existe correlação entre os estados de família. Não há dúvida de que ninguém pode ser detentor do estado de pai se não existir um respectivo filho, bem como não é possível a sustentação concomitante de estado de família antagônico. (NERY, 2014, online)

Desse modo, com o reconhecimento da filiação socioafetiva, é possível afirmar que consoante preceitua a lei 10.406/02 no art. 1.593, o filho socioafetivo uma vez reconhecido judicialmente não ganhará apenas um pai e/ou mãe, mas, haverá a extensão da parentalidade com os outros parentes daquele que o reconheceu. De modo que ocorrerá as mesmas consequências jurídicas do parentesco biológico.

No tocante, ao pátrio poder este é munus público, ou seja, um cargo imposto por lei aos pais, no qual tanto a figura paterna quanto a materna terão obrigação de criar, educar e manter os filhos em sua guarda, bem como lhes garantir a convivência familiar. Em contrapartida, os genitores poderão exigir de seus filhos obediência e respeito.

Cabe observar que esta autoridade parental conferida pelo ordenamento jurídico nada mais é do que o Estado buscando tornar efetivo a proteção integral do menor, vem a estabelecer deveres aos progenitores. 
Submetem-se ao poder familiar os filhos menores de 18 anos, contudo, quando falecidos ou ausentes ambos pais, esses ficaram sob tutela. Ou ainda, quando os filhos já são maiores, contudo, incapazes para o exercício da capacidade civil de fato, sujeitar-se-ão à curatela, podendo neste caso ser qualquer um dos genitores, ou ainda compartilhada.

Logo, apesar da incumbência constitucional dos progenitores ser traçada em assistir, criar e educar os filhos menores, não se pode limitar esse munus público somente à natureza material. Conforme já explanado ao longo desse artigo, ao desenvolvimento da criança é de suma importância zelar pelo afeto, carinho, amor, cuidado, enfim, pela convivência familiar harmoniosa.

\section{DOS DIREITOS PATRIMONIAIS DECORRENTES DO RECONHECIMENTO DA FILIAÇÃO SOCIOAFETIVA}

A legislação tem como papel regular as relações jurídicas existentes na sociedade, no que deverá harmonizar-se com a evolução constante do corpo social. De tal sorte que, como já relatado, o conceito de família não é o mesmo uma vez que houve a desbiologização da definição, haja vista que não mais se restringe aos laços genéticos, recebendo proteção jurídica as relações de afeto, carinho, proteção de pais e filhos sem qualquer vínculo consanguíneo.

Dessarte, com este novo fenômeno jurídico, qual seja, filiação afetiva, haverá de nascer efeitos jurídicos na esfera pessoal e material, no qual não devem tão somente situar-se no plano teórico, mas produzir efeitos práticos no ordenamento jurídico como um todo, repercutindo, inclusive, no âmbito do direito de alimentos e das sucessões.

Já no caso do estado de filiação, sendo matéria que afeta o Direito de Família e Sucessões por consequência, é inviolável que uma decisão judicial negue a legitimidade da posse de estado de filiação. Devendo, assim, o filho socioafetivo ser considerado como herdeiro necessário, sendo qualificado e portador dos 
mesmos direitos, conforme o disposto no art. 1.845 do Código Civil de 2002. (GOULART, 2013, p. 9)

É sabido, que a solidariedade é prevista como objetivo fundamental da República, art. 3ํㅡㄹ inc. I, da Constituição de 1988, no qual busca assegurar aos cidadãos construir uma sociedade livre, justa e solidária.

Tal objetivo constitucional acaba por refletir nas relações familiares, em que busca orientar aos membros que as relações sejam pautadas na afetividade, cooperação mútua, bem como vem a justificar o dever de alimentos por parte dos pais aos filhos menores.

Dessa maneira, uma vez reconhecida a parentalidade sociafetiva não irá restrigir apenas no plano dos direitos pessoais, como já relatado, irá repercutir também nos direitos patrimoniais.

\subsection{Da obrigação de prestar alimentos}

Com fundamento o princípio da solidariedade familiar os genitores tem obrigação legal de prestar alimentos aos filhos menores, no qual decorre do poder familiar nos termos do art. 1.566, IV do Código Civil.

Entre pais e filhos menores, cônjuges e companheiros não existe propriamente obrigação de alimentar, mas dever familiar, respectivamente de sustento e de mútua assistência (CC, art. 1.566, III e IV, e 1.724). A obrigação alimentar também decorre da lei, mas é fundada no parentesco (art.1.694), ficando circunscrita aos ascendentes, descendentes e colaterais até o segundo grau, com reciprocidade, tendo por fundamento o princípio da solidariedade familiar. (GONÇALVES, 2017, p. 507)

Quanto ao vocábulo alimentos é natural que se entenda ser matéria prima consumida pelo ser humano como é fonte de energia e de valor nutricional as funções vitais. No entanto, tal vocábulo possui uma conotação mais ampla, nele sendo compreendidos vestuários, habitação, assistência médica, sustento, instrução e educação. 
Cumpre salientar que até aos 18 anos essa necessidade é presumida, todavia aos filhos maiores é preciso provar que necessita a prestação alimentícia, no qual terá como fundamento o parentesco.

Dessarte, o pai e mãe deverão assistir aos filhos biológicos ou socioafetivos, não somente com o sustento propriamente dito, mas também com vestuários, custeio de atividades recreativas, como também moradia digna.

Outrossim, assistência material deverá ser analisada sob o binômio necessidade - possibilidade, uma vez que não sendo voluntário este dever de sustento, os filhos menores representados ou assistidos legalmente poderão pleitear tal obrigação por meio de ação judicial condenatória à prestação alimentícia.

Ressalta-se que a ação de alimentos não tem o cunho de reconhecer a filiação seja ela decorrente de vínculo biológico ou afetivo, mas o representante ou assististente do menor de 18 (dezoito) anos, poderá cumulativamente pedir o reconhecimento da paternidade e/ ou maternidade. E uma vez sendo declarado o estado filiativo, a condenação a prestação de alimentos deverá ser analisada á luz da necessidade do assistido e possibilidade do assistente.

Dessarte, corrobora com o exposto o entendimento de Lisboa (2013, p.55), " na fixação da prestação de alimentos deve-se observar o binômio necessidade do alimentando e possibilidade do prestador".

Indispensavél salientar que, atualmente, a única prisão civil que o ordenamento jurídico admite é a por dívida de alimentos, no qual se o executado citado não vir a pagar o débito em 3 (três) dias, ou não provar que o fez, bem como não justificar a impossibilidade de efetuá-lo, decretar-lhe-á prisão pelo prazo de 1 (um) a 3 (três) meses, no qual esta será cumprida em regime fechado.

Além de poder exigir dos genitores o dever alimentício, na impossibilidade dos pais terem recursos para atender as necessidades básicas do menor, poderá este querer que os ascendentes na linha reta assumam tal dever, onde os mais próximos excluem os mais remotos, e na ausência destes busca-se a solidariedade familiar aos 
parentes colaterais até o segundo grau, ou seja aos irmãos, seja eles bilaterais ou unilaterias.

Ainda, dispõe a Lei Maior que, os pais tem o dever de assistir ao filhos menores, e os filhos maiores têm o dever de ajudar e amparar os pais na velhice, carência ou enfermidade.

A Carta Magna brasileira destaca, no seu art. 227, ser dever da família, em primeiro plano, assegurar à criança e ao adolescente, com absoluta prioridade, o direito à vida, à saúde, à alimentação, à educação, ao lazer e à profissionalização e no seu art. 229 ser dever dos pais, no desempenho do poder familiar, a mantença dos filhos menores. A solidariedade familiar entre pais e filhos é ilimitada e vai ao extremo de dirigir a venda de bens para cumprimento da obrigação alimentar, forte no princípio constitucional do direito à vida, dentro da dignidade da pessoa humana - arts. $1^{\circ}$ e $5^{\circ}$ da CF. (SILVA, 2003, p.73)

É certo que, uma vez reconhecida a posse de estado de filho na maioridade, ou mesmo que venha a ser reconhecer na menoridade, quando atingir-se a capacidade de fato, os filhos socioafetivos e/ou biológicos terão de amparar aos progenitores para suprir necessidades decorrentes de deficiência etária ou incapacidade laborativa, neste caso há um dever relativo de prestar alimentos, consubstanciado na solidariedade familiar recíproca.

Logo são características da obrigação de prestar alimentos, a irrenunciabilidade e reciprocidade. Como já visto, o dever de prestar alimentos é recíproco entre todos os parentes, bem como este direito não ser pode renunciar podendo o necessitado exigirlo judicialmente.

\subsection{Dos direitos Sucessórios}

Oportuno, neste momento, fazer algumas pontuações acerca dos efeitos sucessórios decorrente do vínculo paterno-filial ou materno-filial afetivo, quando judicialmente reconhecido ou registrado voluntariamente. 
O estado filial afetivo quando convalidado é apto a produzir efeitos jurídicos, haja vista que este ato é dotado de eficácia erga ommes, ou seja, transcende os efeitos entre as partes interessadas e é oponível contra terceiros. Bem como, tem efeito ex nunc, retroagindo a data do nascimento, ou ainda da concepção.

Consoante já aludido, o legislador ordinário estabeleceu o tratamento isonômico entre as proles, no texto do art. 1.593 do Código Civil, em que se determinou que o parentesco não é apenas aquele advento de vínculo consanguíneo, podendo ser amparado legalmente aquele fundado em outra origem, como a afetividade.

Dito isso, o segundo efeito patrimonial consiste na conquista da qualidade de herdeiro legítimo e necessário, vez que o filho socioafetivo reconhecido equipara-se aos demais descendentes na linha reta independentemente da origem filial.

O direito sucessório, conforme estabelecido pelo Código Civil, é a transmissão de bens, direitos e obrigações do falecido aos herdeiros legítimos, necessários, ou ainda testamentários. A herança quando legítima decorrerá por força de lei, e a testamentária por intermedio da manifestacao de ultima vontade, sendo permitido pelo ordenamento a coexistência das duas formas de sucessão.

De acordo com o princípio da saisine, por meio de uma ficção jurídica a herança irá transmitir aos herdeiros na hora da morte do de cujos. E uma vez declarado a sucessão aberta, o processo de inventário terá a finalidade de saldar os créditos com eventuais credores, bem como distribuir os quinhões hereditários.

O ordenamento jurídico pátrio com o objetivo de proteger os bens deixados pelo falecido para os herdeiros legítimos, dispôs que a pessoa ainda em vida só poderá dispor metade de seu patrimônio. Assim, a herança legítima é a parte indisponível, no qual cabe aos herdeiros necessário.

Convém apontar que o herdeiro necessário é o descendente, ascendente ou consorte sucessível, os quais tem direito legítimo a metade do espólio por lei.

Nessa conformidade, o art. 1.829 do Código Civil comanda que a sucessão legítima se defere na seguinte ordem: aos descendentes em concorrência com o 
cônjuge sobrevivente, se este for herdeiro e não meeiro, aos ascendentes em concorrência com o cônjuge, ao cônjuge sobrevivente, e por fim aos colaterais.

Quem primeiro figura na ordem de vocação hereditária são os descendentes (CC 1.829, I). Entre eles os filhos, por serem de grau mais próximo. Como são herdeiros necessários (CC 1.845), fazem jus à legítima, ou seja, à metade do acervo sucessório (CC 1.846). (DIAS, 2016, online)

A lei estabelece que os filhos afetivos reconhecidos são herdeiros necessário, de forma que irão herdar a título universal e terão direito a mesma quota parte que os filhos decorrente de outra origem. Ressalta-se, que a Lei Maior veda quaisquer designações discriminatórias relativas à filiação, estabelecendo tratamento igualitário aos filhos biológicos e socioafetivos.

Acerca do tema, Maria Berenice Dias sustenta que para o filho afetivo ter direito sucessório é necessário que tenha nascido ou ao menos tenha sido concebido antes da abertura a sucessão, tendo em vista que se não for reconhecido não poderá desfrutar da condição de filho e não Ihe será transmito a herança.

Salienta ainda Dias que, é inescusável a propositura da ação para obter o reconhecimento do estado de filiação, que poderá ser após o falecimento do genitor ou genitora, sendo que neste caso poderá cumular o reconhecimento com petição de herança, a fim de resguardar seu quinhão hereditário.

Dessarte, o filho socioafetivo reconhecido poderá pleitear quota parte que the pertence, bem como a nulidade da partilha quando não for chamado a suceder, vez que o legislador the assegurou a qualidade de herdeiro necessário.

Ademais, apropriado é destacar que o estado de filiação pode ser reconhecimento via testamento, conforme disposição do Código Civil art.1.857, bem como tais disposições de cunho não patrimoniais são irrevogáveis mesmo se seja nulo o testamento. Dessa forma, pode o testador reconhecer o filho socioafetivo por disposição de última vontade, e este vir a ter direito à sucessão legítima. 
Outrossim, ainda com relação a vocação hereditária o legislador prevendo que em alguns casos o de cujos não tenha descendentes e ascendentes, e nem cônjuge sobrevivente a herdar. Ordenou que, serão chamados a suceder os colaterais até o quarto grau, em que os mais próximos excluirão os mais remotos.

À vista disso, pode-se observar que o dispositivo 1.841 do Código Civil, garantiu também ao colateral de segundo grau socioafetivo o direito sucessório, a ser chamado a suceder na herança do irmão que não deixou descendentes, cônjuge ou ascendentes.

Ressalta-se que, o reconhecimento da filiação socioafetiva seja por reconhecimento espontâneo perante o Cartório, por testamento, ou judicialmente, não obstam o direito propor ação judicial com proposito de buscar a verdade biológica.

De sorte que, se o filho afetivo reconhecido pleitear posteriormente ação de investigação de paternidade, a fim conhecer sua origem genética, e uma vez declarada judicialmente a paternidade, irá gerar também direitos pessoais e materiais. Como já explanado, caracterizando a multiparentalidade, este terá direito sucessório de ambos os genitores, biológico e socioafetivo.

A condição de filho afetivo não impede a investigação da paternidade biológica. A tendência é admitir a inclusão de nome do pai biológico no registro de nascimento, constituindo-se o que se chama de multiparentalidade. Esta hipótese, inclusive, enseja o reconhecimento de direitos sucessórios com relação a ambos. (DIAS, 2016, online)

Com os novos arranjos familiares e o reconhecimento do estado de filiação afetivo, a tendência não é limitar os direitos da prole frente a multiparentalidade, mas sim assegurar-lhes frente ao princípio da proteção integral e da dignidade da pessoa humana. De modo que não se pode restringir o direito sucessória a uma das filiações, a quem tem mais de um pai ou mais de uma mãe, em que deverá concorrer a ambas heranças se for o caso.

No entanto, vê-se que é necessário ao magistrado usar do poder de cautela ao dirimir lide fundada no reconhecimento post mortem do estado de filiação, seja 
socioafetiva ou biológica, tendo em vista que em alguns casos esse "filho" já se tenha pai registral e venha a pleitear outra parentalidade com o cunho meramente de obter vantagem econômica. Sendo que neste caso, poder-se-ia afirmar que não haveria direito sucessório, ou seja, não teria direito à herança peticionada.

Em contrapartida, em casos onde não há interesse de ordem econômicofinanceira não há que obstar o reconhecimento da parentalidade, uma vez sendo preenchido os requisitos da posse de estado de filho, ou se for o caso comprovado o vínculo parental fundado na hereditariedade biológica, é seu direito constitucionalmente assegurado.

Assim, sendo reconhecido o parentesco afetivo decorrerão inúmeros efeitos na seara jurídica, sendo eles extrapatrimoniais e patrimoniais. Por isso, que o legislador com fundamento na proteção integral da criança ou adolescente, bem como à luz do princípio da dignidade humana, Ihes assegurou como direito material os alimentos e direitos sucessórios, dentre outros.

\section{CONSIDERAÇÕES FINAIS}

Como visto, no presente trabalho, a conceituação de família e as relações de parentesco passaram por grandes transformações ao longo dos anos, e nesse espaço temporal a afetividade ganhou destaque frente à família patriarcal.

É certo que o núcleo familiar outrora era restrito às relações de herança biológica, no qual os filhos seriam aqueles havidos dentro da relação matrimonial, e em decorrência, teriam a carga genética de seus progenitores.

Sucede-se que, com a promulgação da Lei Maior em 1988, introduziu no ordenamento pátrio a concepção de Estado Democrático de Direito, no qual dentro do Direito de Família buscou-se valer de princípios como da dignidade da pessoa humana, solidariedade, igualdade, afetividade, permitindo não restringir as relações de 
parentesco, sejam elas entre pais e filhos e entre parentes com ancestrais em comum, meramente ao vínculo consanguíneo.

Neste contexto, 0 afeto surge como fonte balizar para as famílias contemporâneas, no qual laços de carinho, afeto e solidariedade preponderam frente às relações puramente biológicas. Dessa maneira, a verdade biológica revelou-se insuficiente para o fim assecuratório de uma paternidade e/ou maternidade exercida com responsabilidade e amor.

Destarte, a paternidade e maternidade deixam de ser sinônimos de elo consanguíneo, em que a figura paterna ou materna não pode somente ser qualidade pelo estado biológico, e sim ser reconhecida pelo laço de amor, carinho, proteção, atenção desenvolvida nas relações maternas-filias e paterno-filiais. Pois, pai e mãe são aqueles que criam e não aqueles que concebem.

Advém que, com o surgimento dessa nova modalidade de família e, especificadamente objeto de estudo a filiação, é necessário examinar os direitos desinentes do reconhecimento no mundo jurídico, e os assegurar a quem é sujeito de direito. Haja vista que, tanto o legislador originário, quanto o ordinário, não expuseram de forma clara e precisa os direitos estabelecidos ao filho socioafetivo.

E a partir dessa conjuntura surge a necessidade de estudar os direitos pessoais e patrimoniais inegáveis ao filho socioafetivo através da hermenêutica jurídica e interpretação extensiva, tendo em vista as lacunas na legislação de maneira que esses filhos merecem a mesma proteção jurídica em relação àqueles que possuem vínculo biológico, sendo-Ihes garantido os mesmos direitos e, consequentemente, vedando toda forma de tratamento desigual.

Configurada a filiação socioafetiva, o filho afetivo tem o direito ao nome, o estabelecimento do poder família, à multiparentalidade (se configurada no caso concreto), o direito aos alimentos, bem como o de ser chamado à ordem sucessória.

Portanto, a composição familiar meramente decursiva de elo genético é mitigada frente ao perfil do acolhimento e do afeto, em razão do qual não podendo mais 
afirmar que o grupo familial se formar em razão tão somente da consanguinidade, mas primordialmente em virtude da afetividade.

Por fim, defende-se nesse artigo que o estado de filiação afetivo gera efeitos e deve ser reconhecido. Entretanto, enquanto não for regulado pelo legislador, ou seja, não houver um reconhecimento expresso por parte do ordenamento jurídico, incumbirá ao magistrado identificar e proteger essa relação fática de filiação.

\section{REFERÊNCIAS}

BRASIL. Constituição da República federativa do Brasil de 1988. Disponível em: <http://www.planalto.gov.br/ccivil_03/constituicao/constituicao.htm>. Acesso em: 10 sete. 2017.

. Conselho da Justiça Federal. Enunciados. Disponível em:

<http://www.cjf.jus.br/enunciados/>. Acesso em: 10 out. 2017

. Decreto no 99.710, de 21 de novembro de 1990. Promulga a Convenção sobre os Direitos da Criança. Brasília: Congresso Nacional, 1990. Disponível em:< http://www.planalto.gov.br/ccivil 03/decreto/1990-1994/D99710.htm>. Acesso em: 10 jul. 2017.

. Lei no 8.069 , de 13 de julho de 1990. Dispõe sobre o Estatuto da Criança e do Adolescente e dá outras providências. Brasília: Congresso Nacional, 1990. Disponível em:

< https://www.planalto.gov.br/ccivil_03/leis/L8069.htm>. Acesso em: 10 jul. 2017.

. Lei no 10.406, de 10 de janeiro de 2002. Institui o Código Civil. Brasília: Congresso Nacional, 2002. Disponível em:

$<$ https://www.planalto.gov.br/ccivil 03/LEIS/2002/L10406.htm>. Acesso em: 11 jul. 2017.

.Superior Tribunal de Justiça (STJ). REsp 1.059.214/ RS. Relator: Min. Luis Felipe Salomão. Data de Julgamento: 16/02/2012.

. Supremo Tribunal Federal (STF). RE 898.060/SP. Relator: Min. Luiz Fux. Data do julgamento 29/09/2016. 
Supremo Tribunal Federal (STF). ARE 692.186/DF. Relator: Min. Luiz Fux. Data de Julgamento: 04/09/2014.

ALMEIDA, Priscilla Araújo de. Efeitos da paternidade socioafetiva no ordenamento jurídico brasileiro. 77f. Trabalho de Conclusão de Curso (Monografia) - Especialização em Prática Judicante, Universidade Estadual da Paraíba, João Pessoa, 2015.

ANDRADE, Denise de Paula. Filiação Socioafetiva Decorrente do Reconhecimento Voluntário da Paternidade e a Impossibilidade de sua Desconstituição. Revista Nacional de Direito de Família e Sucessões, Porto Alegre, v. 1, n. 3, p. 35 - 50, nov./dez. 2014. Disponível em: <www.lex.com.br>. Acesso em: 10 set. 2017.

BUCHMANN, Adriana. A paternidade socioafetiva e a possibilidade de multiparentalidade sob a ótica do ordenamento jurídico pátrio. 79f. Trabalho de Conclusão de Curso (Monografia)- Direito, Universidade Federal de Santa Catarina, 2013.

CASSETTARI, Christiano. Multiparentalidade e parentalidade sociafetiva: efeitos jurídicos. 3. ed . São Paulo: Atlas, 2017.

DOMINGOS, Sergio. A família como garantia fundamental ao pleno desenvolvimento da criança. Revista de direito de infância e juventude, v.1/2013, p. $251-279$, jan.-jun. 2013.

DIAS, Maria Berenice. Manual de direito das famílias. 12. ed. São Paulo: Revista dos Tribunais, 2017.

DIAS, Maria Berenice. Manual das sucessões. 4. ed. São Paulo: Revista dos Tribunais, 2016.

FACHIN, Luiz Edson. Posse de estado de filho e a sociafetividade análise constitucional da filiação. Revista dos Tribunais, v.2, p. 109, Jan / 2012.

GONÇALVES, Carlos Roberto. Direito civil brasileiro: direito de família. v.6. 14. ed. São Paulo: Saraiva, 2017.

GOULART, Fabiane Aline Teles. O reconhecimento da Filiação Socioafetiva com seus Efeitos Sucessórios. Revista Brasileira de Direito das Famílias e Sucessões, Porto Alegre: Magister; Belo horizonte: IBDFAM, ano XIV, n. 32, p. 17, fev/mar 2013.

Disponível em: <www.lex.com.br>. Acesso em: 10 set. 2017. 
LISBOA, Senise. Manual de direito civil: direito de família e sucessões. v.5. 8. ed. São Paulo: Saraiva, 2013.

MALUF, Carlos Alberto Dabus. Parecer - As relações de parentesco na contemporaneidade - Prevalência a priori entre a parentalidade socioafetiva ou biológica - Descabimento - Definição em cada caso concreto do melhor interesse dos filhos - Multiparentalidade - Reconhecimento em casos excepcionais. vol. 33, p. $19-43$, jan - jun.2014.

NADER, Paulo. Curso de Direito Civil: Direito de Família. v.5. 7. ed. Rio de Janeiro: Forense, 2016.

NERY, Rosa Maria de Andrade. Manual de direito Civil: Família. 1. ed. São Paulo: Revista dos Tribunais, 2014.

OLIVEIRA, Beatriz Rosana Gonçalves de; COLLET, Neusa. Criança hospitalizada: percepção das mães sobre o vínculo afetivo criança-família. Revista Latino-Americana de Enfermagem, Ribeirão Preto, v. 7, n. 5, p. 95-102, dec. 1999. Disponível em: <https://www.revistas.usp.br/rlae/article/view/1412/1444>. Acesso em: 13 ago. 2017.

PEREIRA, Rodrigo da Cunha. Famílias Ensambladas e Parentalidade Socioafetiva-a Propósito da Sentença do tribunal Constitucional, de 30.11. 2007. Revista Brasileira de Direito das Famílias e Sucessões. Porto Alegre: Magister, v. 7, n. 10, 2009. Disponível em: <www.lex.com.br>. Acesso em: 10 set. 2017.

PRATTA, Elisângela Maria Machado; SANTOS, Manoel Antonio dos. Família e adolescência: a influência do contexto familiar no desenvolvimento psicológico de seus membros. Psicologia em Estudo, v. 12, n. 2, p. 247-256, 2007.

RODRIGUES, Geraldo Silva; CONCIANI, Marcos Vinicius De Souza. A família socioafetiva: uma visão crítica acerca das novas entidades familiares vinculadas ao afeto. Revista Intervenção, Estado e Sociedade, Ourinhos - SP, v. 2, n. 1, p. 112-127, mar. 2015. Disponível em: <http://projuriscursos.com.br/revista/index.php/revistaprojuris/article/view/38>. Acesso em: 13 ago. 2017.

SILVA, Luana Babuska Chrapak da. Paternidade Socioafetiva e a obrigação alimentar. 90f. Tese (Monografia) - Bacharelado em Ciências Jurídicas e Sociais, Pontífica Universidade Católica do Rio Grande do Sul. Porto Alegre, 2003.

TARTUCE, Flávio. Direito Civil: Direito de Família. v.5. 12. ed. rev., atual. e ampl. Rio de Janeiro: Forense, 2017. 
VENOSA, Sílvio de Salvo. Direito Civil: direito de família. v.5. 17. ed. São Paulo: Atlas, 2017.

ZENI, Bruna Schlindwein. A evolução histórico-legal da filiação no Brasil. Direito em debate, v.18, n.31, p. 59- 80, 2009. 